\title{
POR QUE SOURIAU?
}

\author{
Daisi Malhadas \\ UNESP/Araraquara
}

\begin{abstract}
RESUMO
A proposta deste artigo é mostrar o interesse de se estudar As duzentas mil situaçōes dramáticas, de Etienne Souriau. Primeiramente, porque a obra não propõe apenas um modelo actancial formal de situações dramáticas, mas lhes examina as funções dramatúrgicas segundo critérios estéticos. Trata-se, além disso, de uma teoria endereçada a dramaturgos, mas que é também útil à análise crítica e à encenação de peças.
\end{abstract}

\section{PALAVRAS - CHAVE}

Souriau, situaçōes dramáticas, modelo actancial

NOTA INTRODUTÓRIA

Greimas, em sua análise de Propp (Morfologia do conto popular russo) e de Souriau (As duzentas mil situações dramáticas), afirma:

É impressionante, importa notá-lo agora, ver como a relação entre sujeito e objeto, que obtivemos com tanta dificuldade, sem pleno resultado, aparece aqui com a mesma investidura semântica nos dois inventários: a do "desejo".

Eis uma afirmação que avalia positivamente a base do que Greimas chama de inventário de actantes tanto em Propp como em Souriau.

Greimas considera ainda que a reflexão de Souriau é coerente e que seu interesse

consiste no fato de ter ele mostrado que a interpretação actancial podia se aplicar a um tipo de narrativas - as obras teatrais - bem diferente do conto popular e que seus resultados podiam ser comparáveis aos primeiros. ${ }^{2}$

Apoiados ou não nas consideraçōes greimasianas, há dramaturgos e estudiosos de teatro que reconhecem no sistema de forças das situações dramáticas de Souriau um modelo de invenção dramática e de crítica teatral.

Anne Ubersfeld afirma que se deve a Souriau e a Greimas o fato de sabermos construir o modelo actancial para o teatro - modelo que ela própria empregou para

\footnotetext{
' GREImAS. Semântica estrutural, pesquisa de método, p.231.

${ }^{2}$ IBIDEM. p. 229.
} 
descobrir no teatro de Victor Hugo uma estrutura ${ }^{3}$ e reelaborou em seus cursos no Institut d'Etudes Théâtrales da Universidade de Paris III e em seus estudos teóricos. ${ }^{4}$

Patrice Pavis observa que Souriau teve "l'extrême mérite de distinguer des forces qui sont très exactemente présentes dans tout l'univers dramatique". 5

Tanto A. Ubersfeld como $\mathrm{P}$. Pavis reelaboraram, à luz da semiologia, o sistema de Souriau. Na trilha deles, com algumas pequenas alterações, seguem R. Monod (1997) e J-P. Ryngaert (1991). Não se pode dizer que esses autores apenas propõem esquemas diferentes - quadros, flechas - para as funções dramatúrgicas e as conseqüentes situações dramáticas. As formulações gráficas diferentes pressupõem concepçōes diferentes das funções. Não vamos, entretanto, discutir aqui nem a reelaboração greimasiana, nem as interpretaçōes e aplicaçōes que surgiram a partir de Souriau e Greimas.

A citação de autores que tiveram Souriau como referência no desenvolvimento de suas teorias é feita para registrar a importância desse filósofo nas pesquisas de teatro. Não visa, então, este trabalho discutir, por exemplo, se a função de Árbitro deve ser entendida como Destinador ou nāo, se a melhor visualização da situação dramática - ou modelo actancial, se assim se deve chamar - é na seqüencia proposta por Souriau ou nos esquemas Ubersfeld/Pavis/Monod... - esquemas, aliás, nem sempre imprescindíveis.

O que importa aqui é tentar perceber qual a contribuição que a teoria de Souriau em As duzentas mil situações dramáticas - obra que nem a semiótica nem a semiologia relegaram - trouxe para a estética teatral. Que luz — teoria implica visão - essa obra lança nos caminhos da dramaturgia e da encenação? Eis a questão que orienta este estudo.

Para uma discussão sobre as funçōes dramatúrgicas, para explicá-las e aplicálas, recomendam-se, além dos autores citados, Renata Pallottini, que, em Dramaturgia - construção do personagem, discute as situações dramáticas como orientação dramatúrgica, e Lídia Fachin, que em tese de doutorado intitulada Théâtre et éducation chez George Sand, explica e emprega o sistema de Souriau, fazendo-o dialogar com a semiologia.

\section{A proposta de Souriau}

No início do Prefácio, Souriau já delimita sua proposta: na arte do teatro, estudar as "situaçōes". ${ }^{6}$ Essa delimitação apóia-se numa apreciação estética com uma finalidade, pois trata-se de uma questão que tem muita importância ${ }^{7}$ na invenção dramática.

A apreciação estética evidencia-se mais ainda no objetivo de sua proposta, expresso em quatro itens:

1 - distinguir (...) as grandes funções dramatúrgicas;

2 - estudar dessas funções as principais combinações;

\footnotetext{
${ }^{3}$ UBERSFELD. Le roi et le Bouffon, p.399.

${ }^{4}$ UBERSFELD. Lire le théâtre, p.67 ss.

${ }^{5}$ Pavis. Problèmes de sémiologie théâtrale, p.91.

${ }^{6}$ Souriau. As duzentas mil situaçōes dramáticas, p.7.

${ }^{7}$ Todas as expressōes que denotem apreciação estética estão grifadas em negrito.
} 


\section{3 - buscar dessas combinaçōes as razões das propriedades estéticas;}

4 - observar como as situaçōes, pelo encadeamento e por modificações, fazem caminhar a ação teatral. ${ }^{8}$

Esse percurso Souriau apresenta como pertinente "à teoria e à prática do teatro, do ponto de vista da criação". ${ }^{9}$ Conclui-se, portanto, que sua proposta se endereça a dramaturgos. Isto se evidencia quando a possibilidade de haver mais de 200 mil situaçōes dramáticas aponta para uma "perspectiva tranqüilizadora para dramaturgos de hoje e de amanhã". ${ }^{10}$

Ao expor as funçōes dramatúrgicas, receando que o leitor as considere um estudo "genérico", "abstrato", "teórico", ou mesmo "esquelético", argumenta que os "dados" apresentados "resultam de uma observação concreta do fato dramático"." Resultam, portanto, de análise de peças. Ao longo da obra, ao distinguir funções, ao estudar combinações, ao buscar os valores estéticos das situaçōes, ao observar como estas encaminham a ação, sempre parte da análise de peças teatrais. Parte do já criado, para estabelecer a orientação para criar. Então, o percurso traçado pelos objetivos de sua proposta é pertinente também à teoria e à prática do teatro. Os critérios que orientam a criação podem se aplicar ao estudo de uma peça de teatro, propiciando tanto a apreciação crítica, quanto a montagem cênica.

Como Aristóteles na Poética, Souriau desenvolve uma teoria ao mesmo tempo descritiva e normativa. Por isso, como a Poética, As duzentas mil situações dramáticas é uma obra que expõe critérios de composição importantes do ponto de vista "das técnicas do autor dramático"12 e do ponto de vista das técnicas do crítico dramático, assim como do diretor, do adaptador e do amante de teatro que se deleita com o estudo de peças.

\section{SITUAÇÄ́ DRAMÁTICA}

\section{1. Macrocosmo/microcosmo}

Para começar a conceituar a situação dramática, Souriau vai mostrar a importância da relação macrocosmo/microcosmo.

O que se passa em cena compōe o microcosmo. Esse "microcosmo cênico", ${ }^{13}$ como sempre Souriau o nomeia, tem um conteúdo que "deve, por si só, sustentar e produzir a reconstituição do universo da obra - o macrocosmo teatral". ${ }^{14}$ Ao expor como se estabelece essa relação, isto é, como o macrocosmo acede à cena, Souriau introduz as críticas, as normas, os critérios que indicam o pior e o melhor:

- a "forma de narração" para conduzir à cena os "acontecimentos essenciais" que se passam fora dela é considerada imperfeição grave do sistema; ${ }^{15}$

\footnotetext{
3. SOURIAU. As duzentas mil situações dramáticas, p.8.

${ }^{9}$ IBIDEM. p.8.

${ }^{10}$ IBIDEM. p. 13.

"IBIDEM. p.81.

${ }^{12}$ IBIDEM. p.8.

13 A redundância vem sublinhar que o microcosmo abrange apenas o que se passa em cena. Pode-sc comparar ao conceito de "espaço mimético" de M. Issacharoff (1985, p. 69ss).

14 SOURIaU. As duzentas mil situações dramáticas, p.18.

${ }^{15}$ IBIDEM.
} 
- o fato de "o caráter dramático do que acontece em cena" dever repousar "na sua relação com a que está fora de cena", ${ }^{16}$ não significa que acontecimentos importantes do macrocosmo não possam ficar ausentes do microcosmo, desde que essa invisibilidade gere uma expectativa dramática; Souriau dá, como exemplo, o expediente do duelo no exterior; em cena, os personagens vivem a expectativa; o que ocorre no exterior interessa pela modificação que vai gerar nas relações dos personagens; quando essa expectativa cria em cena uma "tensão moral" que supera o acontecimento que ficou fora, tem-se uma situação totalmente louváveli ${ }^{17}$

- de um lado, o microcosmo sustenta o macrocosmo - desde que seja "estelarmente central", isto é, seu foco é "o do mundo inteiro" - ; de outro lado, o universo da obra deve ultrapassar o universo cênico, para que "haja verdadeiramente teatro"; ${ }^{1 s}$ portanto, o dramaturgo e o crítico têm aqui a primeira norma: é fundamental a relação entre o "cosmos da obra e seu pequeno núcleo estelar de personagens"; ${ }^{10}$ de um lado há o mundo, de outro lado um núcleo, ligados de tal modo que "nada acontece num que não tenha resposta no outro"; trata-se da "relação estelar e interestrutural do microcosmo e do macrocosmo teatral"; ${ }^{20}$ dessa relação depende a avaliação estética: esse "dispositivo estelar", dado artístico de primordial importância, constitui um primeiro aspecto do que é uma situação.

Pode-se dizer, então, que essa relação macrocosmo/microcosmo da situaçāo dramática é determinante do valor da obra, de seu ingresso no âmbito das obras universais, daquelas que têm valor, por sua integração com o cosmos, em qualquer espaço e tempo.

\subsection{Interesse artístico}

Considerações sobre o interesse artístico também informam a reflexão introdutória à conceituação de situação. As peças podem ser esteticamente importantes - ter interesse artístico mesmo quando se classificam no que Souriau nomeia "teatro parcial": teatro de caráter ou de ambiente, de idéias ou de situação. ${ }^{21}$ As peças que reúnem todos esses pontos de vista constituem as obras-primas do teatro.

Souriau propõe, então, que o estudo das situaçōes se aplique

- às obras dramáticas em que as situações é que constituem o valor artístico predominante,

- às obras-primas em que, se as situações não são responsáveis por todo o interesse artístico, "são, no entanto, um dos fatores autênticos e importantes desse interesse". ${ }^{22}$

Essas consideraçōes delimitam a aplicação do estudo das situaçōes a certas peças. Ao esclarecer, no entanto, que o estudo das situações leva a perceber o essencial da obra teatral, Souriau amplia essa aplicação a todo tipo de peça, pois esta só existe se houver ação que, por sua vez, se constitui de situações:

\footnotetext{
${ }^{16}$ SOURIAU. As duzentas mil situaçōes dramáticas, p.18.

${ }^{17}$ IBIDEM.

${ }^{18}$ IBIDEM. p. 20.

${ }^{19}$ IBIDEM. p. 25.

${ }^{20}$ IBIDEM. p. 24.

${ }^{21}$ IBIDEM. p. 27.

22 IBIDEM. p. 28.
} 
Qualquer que seja o interesse despertado pelo universo teatral que nos é proposto personagens, caracteres, ambiente, cstrutura de conjunto, atmosfera moral, psicológica ou social - só haverá peça, se, uma vez colocados esses elementos (particularmente o grupo de personagens), chegar a estabelecer-se entre eles uma ação, e se esta ação, fio condutor que os leva desde que a cortina se abre até o desenlace, não se contentar em conduzir paralelamente os destinos dos personagens, mas sim escorá-los, por assim dizer, uns nos outros; colocá-los, em certos momentos exclusivos, intensos, patéticos, naqueles dispositivos ao mesmo tempo arquitetônicos e dinâmicos que constituem as situações; e fizer da apresentaçāo intensa, brilhante, e da sucessão caleidoscópica dessas situações um dos recursos artísticos essenciais da obra. ${ }^{23}$

\section{3. ação/situação/forças}

Insistindo no quanto a ação é essencial no teatro, Souriau mostra a necessidade da ação e da situação interagirem:

Una perpétua emergência de acontecimentos arbitrários não produz a ação teatral.(...) É preciso, para que haja ação, que à pergunta: Que aconteceu em seguida?, a resposta resulte forçosamente (...) da próxima situação e dos dinamismos interiores de cada momento cênico. ${ }^{24}$

Percebe-se nessa resposta, que resulta forçosamente de uma dinâmica interna, a semelhança com a concepção aristotélica de enredo. ${ }^{25}$ Para Aristóteles, num enredo uno e inteiro, os atos se concatenam de tal modo que nenhum pode ser deslocado ou suprimido, sem que o todo seja subvertido. A um ato responde necessariamente outro. ${ }^{26}$

As reflexōes de Souriau sobre a necessidade de ação e situação interagirem encaminham para a conceituação de situação:

Una situação dramática é a figura estrutural esboçada, num momento dado da ação, por um sistema de forças - pelo sistema das forças presentes no microcosmo, centro estelar do universo teatral; e encarnadas, experimentadas ou animadas pelos principais personagens daquele momento da açāo. ${ }^{27}$

Com essa conceituação, Souriau introduz as forças que são as funções dramatúrgicas, aquelas que geram o drama, no sentido primeiro de ação. ${ }^{28}$

\section{FUNÇÕES DRAMATÚRGICAS}

Chamo de Função Dramatúrgica o modo específico de trabalho em situação de um personagem: seu papel próprio enquanto força num sistema de forças. ${ }^{29}$

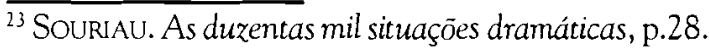

${ }^{24}$ IBIDEM. p. 32.

${ }^{25}$ Souriau grifa "forçosamente" e acrescenta, entre parênteses, "como Pirandello gostava de dizer", sem fazer nenhuma referência a Aristóteles.

${ }^{26}$ Cf. Poética, 51 a 32.

${ }^{27}$ Souriau. As duzentas mil situaçōes dramáticas, p.38.

${ }^{23}$ Nessa primeira passagem em que trata das forças, Souriau as nomeia "funções dramáticas" (p. 38-39); no capítulo em que trata especialmente delas (cap. 2), desde o próprio título chama-as de "funções dramatúrgicas", o que é mais adequado: as funções operam os mecanismos - fazem o trabalho-que criam a situação dramática.

${ }^{29}$ SOURIAU. As duzentas mil situações dramáticas, p.52.
} 
À conceituação de função dramatúrgica logo se acrescenta uma apreciação estética: "numa boa situação, cada personagem tem uma força específica". ${ }^{30}$ Constatase, no estudo de cada função, que essa apreciação não quer dizer que cada personagem só pode desempenhar o papel de uma única função. ${ }^{31} \mathrm{O}$ que não pode é haver um personagem sem função. Por outro lado, a ausência de uma funçāo dramatúrgica importante no microcosmo constitui-se num pecado contra a arte. ${ }^{32}$ No entanto uma função pode figurar no microcosmo "por procuração ou delegação" e ser "dramaticamente muito valiosa". ${ }^{33}$

Desse modo, apreciando o que pode ser positivo ou negativo esteticamente, Souriau introduz as funçōes dramatúrgicas, cujo elenco é o seguinte: ${ }^{34}$

- a Força temática orientada

- o Representante do bem desejado

- o Obtentor do bem

- o Oponente

- o Árbitro

- o Adjuvante

\section{a Força temática orientada}

(Função que gera toda situação dramática.)

Esta funçāo, encarnada num personagem, expressa o desejo de algo, orienta-se para alguma coisa, para obtê-la — no caso da ambição — , ou para evitá-la — no caso do temor. Além de gerar toda a tensão dramática, ou por isso mesmo, supomos que, por sua orientação para um determinado valor, essa função estabelece o tema da peça, como explicita o termo "temático" em seu nome. Dificilmente essa função pode estar ausente da peça, isto é, pode deixar de encarnar-se num personagem que deverá estar presente no microcosmo. ${ }^{35}$ No entanto, pode haver um retardamento na entrada em cena de quem a encarna, o que pode gerar mistério, expectativa, com efeito teatral de primeira ordem, pois caracteriza uma situação notável, poderosa e original. ${ }^{36}$

Sua ausência até o final da peça para não frustrar a expectativa, deve ser preparada, explicitando que a força que produz toda a tensão do drama não poderá comparecer encarnada numa presença humana. Para Souraiu, se a "atmosferizaçāo" for completa, o trabalho estético então atingirá extraordinária dimensão. ${ }^{37} \mathrm{~A}$ situação se tornará esteticamente mais complexa quando o árbitro estiver encarnado, já que lhe cabe propiciar ou impedir que a Força temática ausente consiga o bem desejado.

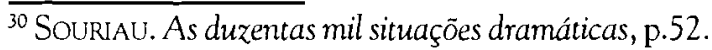

${ }^{31}$ Souriau considera importante o investimento de várias funções num só personagem respeitando-se um limite que ultrapassado pode trazer prejuízo artístico. Já a separação completa - cada personagem uma função - pode ser a força e a fraqueza da peça ao mesmo tempo.

32 SOURIAU. As duzentas mil situações dramáticas, p.56.

${ }^{33}$ IBIDEM.

${ }^{34} \mathrm{~A}$ terminologia das funções está reduzida ao essencial, sem os termos nem os sinais astrônomo-astrológicos, empregados por Souriau, por serem sobretudo importantes para montar os esquemas das situações dramáticas, objetivo que não se inclui na proposta deste artigo. Ao termo "Adjuntor" da tradução adotada preferiu-se "Adjuvante".

${ }^{35}$ SOURIAU. As duzentas mil situaçōes dramáticas, p.138.

${ }^{36}$ IBIDEM. p.139.

${ }^{37}$ IBIDEM.
} 


\section{o Representante do bem desejado}

(Função para a qual se orienta a Força temática.)

A tendência da Força temática obrigatoriamente orienta-se para um "bem desejado". Este não precisa necessariamente estar encarnado num personagem no microcosmo. Mesmo que tenha apenas um investimento no macrocosmo, essa função será dramatúrgica. O investimento, então, pode ser pessoal - Deus, por exemplo ou impessoal como a liberdade, a paz... Em cena, algum acessório pode simbolizar o bem desejado: uma coroa ou um cetro pelo poder que se ambiciona. Este emprego de acessórios, no entanto, se é feliz cenicamente, resulta do que Souriau classifica como "queda na matéria" e que considera um recurso não dramatúrgico. ${ }^{38}$ Para gerar drama, é preferível o recurso de um personagem que no microcosmo fale em nome do Representante do bem desejado enquanto este permanece no macrocosmo. ${ }^{39}$

De qualquer modo, Souriau considera que a supressāo dessa força, mesmo que freqüente, é dificilmente afortunada. A supressão é dificultada não só por tratar-se de interessante força cênica, mas também porque raramente aparece isolada. Em geral, o personagem que a encarna também assume outra função. ${ }^{40}$

\section{o Obtentor do bem}

(Função para a qual vai o bem desejado pela Força temática.)

Quem encarna a Força temática orientada pode desejar o bem para si ou para outro. No primeiro caso, ele concentra em si duas funções dramatúrgicas: Força temática orientada e Obtentor do bem - como no caso do tema do amor erótico. No segundo, cada uma dessas funções é exercida por um personagem - como no caso do tema do amor materno. Ambos os casos sāo considerados dramaturgicamente válidos, e mesmo grandes potências teatrais. ${ }^{41}$

No caso de um personagem encarnar apenas a função de Obtentor do bem, há pouco dinamismo, embora possa atrair a simpatia do público. Neste caso, adverte Souriau, ocorre um importante problema de estética teatral, que se pode, simplificando, formular assim: o interesse do espectador por um personagem é uma força dramatúrgica? Em outros termos: confere-lhe um dinamismo de ação? ${ }^{42}$

Souriau, embora reconheça que "uma força atrativa não é nula" adverte que "não é puramente dramatúrgica" por depender da intervenção do espectador. ${ }^{43}$

A questão é esteticamente delicada e até mesmo grave; e os melhores artistas recusam-se muitas vezes a reconhecer essa idéia como válida - e, por exemplo, a modificar o desenlace que foge da natureza das coisas, exigido, intrinsecamente pelo universo teatral, para poupar o público de um acontecimento penoso demais... ${ }^{44}$

Não seria, portanto, esse o recurso para enriquecer a função do Obtentor do bem que, apesar de essencial, pode ser fraca esteticamente. ${ }^{45}$

\footnotetext{
${ }^{35}$ SOURIAU. As duzentas mil situações dramáticas, p.63.

${ }^{3 \circ}$ IBIDEM.

${ }^{40}$ IBIDEM. p. 140.

${ }^{41}$ IBIDEM. p. 65.

${ }^{42}$ IBIDEM.

${ }^{43}$ IBIDEM. p. 66.

${ }^{44}$ IBIDEM. p. 66-7.

${ }^{45}$ IBIDEM. p. 67.
} 
A ausência dessa função no microcosmo pode ter duas conseqüências: enfraquecer ainda mais a função ou ser um recurso válido como no caso do tema do "complô contra o ausente". ${ }^{46}$

\section{o Oponente}

(Função que se opõe à Força temática.)

Não haveria drama - ação - se à Força temática orientada não se opusesse algum obstáculo, pois essa tendência só é dramatúrgica "quando encontra resistência". ${ }^{47}$

Para que haja o que Souriau chama de dramaturgia integral, o Oponente deve estar encarnado num personagem no microcosmo. ${ }^{48}$ Pode, no entanto, permanecer cósmico - como a opinião pública — ou ter investimentos físicos - como o nariz de Cyrano.${ }^{49}$ No entanto, para que não ocorra enfraquecimento dramático, convém que, pelo menos um delegado da entidade impessoal, como é o caso da opinião pública, exerça a ação concreta em cena.

A opiniăo pública como oponente individual serve também como exemplo para o tema do "Obstáculo imponderável" e "atmosfericamente presente" que, se for "invulnerável" e "inexorável", torna-se trágico, por sua maior intensidade estética. O mesmo pode dizer-se do oponente moral, o "Proibido". 50

Souriau menciona também investimentos materiais, como símbolos de oponentes: uma porta, um muro, a força da gravidade e acessórios que podem deter, por respeito - caso do cetro, da coroa - ou por mau agouro. ${ }^{51}$

Souriau não vê inconveniente dramatúrgico no desdobramento do obstáculo em dois ou três oponentes. O risco de a força perder o vigor que lhe confere a unidade pode ser compensado pela força "aritmética", sobretudo se o obstáculo for humano. No entanto, deve-se evitar a "multidão de oponentes", a não ser que se queira provocar a comicidade. ${ }^{52}$

\section{o Árbitro}

(Função que tem o poder de conceder ou de recusar o bem.)

Como Árbitro da situação dramática, esta função exprime a força que decide da atribuição do bem..$^{53}$

Para Souriau, o valor dramatúrgico mais intenso do Árbitro se mostra quando este atua em relação com a Força temática orientada e com o Oponente, mesmo que não intervenha necessariamente como árbitro entre dois rivais. ${ }^{54}$

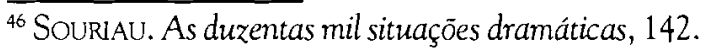

${ }^{47}$ IBIDEM. p.67.

${ }^{48}$ IBIDEM. p. 68.

${ }^{49}$ IBIDEM. p. 67.

${ }^{50}$ IBIDEM. p. 140.

${ }^{51}$ IBIDEM.

52 IBIDEM. p. 70.

${ }^{53}$ Embora, como foi dito, nāo se tenha a intenção de discutir comparando o modelo de Souriau com outros modelos actanciais, convém apontar quanto esta concepção de Árbitro difere da concepção de Destinador de Greimas e outros. Por isso, A. Ubersfeld engana-se na crítica que faz a Souriau ao tratar o Árbitro como uma 7ª função (sic) destituída pelo Destinador (Lire le théâtre, p.69).

${ }^{54}$ Sourdau. As duzentas mil situações dramáticas, p.71-72.
} 
O Árbitro pode atuar apenas no macrocosmo - como o destino, os deuses mas é quando figura no microcosmo que se torna uma grande potência dramatúrgica. ${ }^{55}$ Trata-se da função mais difícil de suprimir do microcosmo, pois seria "fazer depender a decisão, o acontecimento essencial, de uma força ausente", o que exige "labor extraordinário" para ser dramático. ${ }^{56}$

Quando aparece no final da peça, faz correr o risco dos desenlaces de bastidores, com oráculos e deuses invisíveis, ou, o que é pior com deus ex machina sem teofania. Há, no entanto, a possibilidade de uma "presença invisível" exercer a arbitragem por exemplo, uma sombra - que desperta interesse sob o tema da "Expectativa de um sinal". Souriau conclui lembrando que se o Árbitro é "potência resolutiva, no decorrer da ação seu papel geralmente é dinâmico, ao manter em suspenso a decisão: hesitação nele, expectativa para os outros". ${ }^{57}$

\section{o Adjuvante}

(Função que reforça outra função.)

Como reforço de outra função, o Adjuvante assume um "papel de co-interessado, cúmplice ou auxílio e salvador", resultando em duplicação da função que reforça. ${ }^{58}$

Pode haver um Adjuvante para cada uma das funções, pois todas são suscetíveis de duplicaçāo, mas além de un drama ser mais intenso quanto mais concentrado em pequeno número de personagens, artisticamente a duplicação de uma só força - ou no máximo de duas - constitui um recurso poderoso..$^{59}$ Deve-se, sobretudo, evitar a duplicaçāo concomitante de duas funçōes, pois o resultado é o impasse do equilíbrio; por exemplo, a Força temática e seu Oponente contarem, ao mesmo tempo, com Adjuvantes. ${ }^{50}$

As duplicaçōes mais favoráveis à intensificação da dramaticidade são as de Adjuvante da Força temática ou do Oponente. No entanto, a duplicação do Árbitro só se revela positivamente dinâmica em desenlace. Em situações anteriores, pode confundir-se com un reforço do obstáculo ou ser apenas um apoio moral do atribuidor do bem, sem representar um reforço no poder de decisão. ${ }^{61}$

Pode ocorrer também entre uma força e o Adjuvante o que Souriau chama de mudança de situação, uma interversão (grifado no original). Cita como exemplo: Macbeth, na peça do mesmo nome, é a Força temática, sendo Lady Macbeth sua Adjuvante; esta, quando aquele hesita no assassínio do rei, assume a função da Força temática; depois, cada um retoma sua função inicial. ${ }^{62}$

O Adjuvante, por sua condição de duplicação de uma força, não se constitui como indispensável, ocorrendo até que sua supressão revele-se um recurso dramatúrgico importante, com efeitos artísticos tais como:

\footnotetext{
${ }^{55}$ Souruau. As duzentas mil situações dramáticas, p.73.

${ }^{56}$ IBIDEM. p. 141.

${ }^{57}$ IBIDEM. p. 141-142.

${ }^{58}$ IBIDEM. p. 73.

${ }^{59}$ IBIDEM. p. 74.

${ }^{60}$ IBIDEM.

${ }^{61}$ IBIDEM. p. 76-77.

${ }^{62}$ IBIDEM. p. 75.
} 
carência de Salvador (Obtentor do bem)

sozinho, defesa, contra todos (Oponente)

sozinho, na ofensiva, contra todos (Força temática orientada)

desamparo na decisão (Árbitro)

solidão (Representante do bem desejado) ${ }^{63}$

o ponto de vista

"Devemos fazer dele uma função à parte? Inicialmente tínhamos pensado nisso." Assim se expressa Souriau a respeito do ponto de vista que considera fato muito importante e categoria arquitetônica essencial. ${ }^{64}$

O que o demoveu de criar com o ponto de vista uma 7’ funçāo, a 7ª nota da escala musical, que completaria "as sete cordas da lira dramática", foi perceber que "esse signo sempre designava um personagem já provido de outras forças, e jamais podia ser isolado". ${ }^{55}$ Então como um "gênero de dispositivo" (grifado no original) dessas forças, o ponto de vista é a porta de entrada por onde o espectador vê em perspectiva o interior da situação. O personagem assim designado torna-se o protagonista de ponto de vista. ${ }^{66}$ Podem ocorrer "transposiçōes de ponto de vista", isto é, de uma situação dramática para outra pode mudar o protagonista de um ponto de vista. ${ }^{67}$

No estudo das funçōes, em alguns casos, Souriau faz observaçōes estéticas sobre o ponto de vista. Quando trata do Oponente, exemplificando com o tema da Rivalidade, considera que "quase sempre é o ponto de vista que então produz a assimetria" necessária para encaminhar a decisão. ${ }^{63}$ No caso da supressão do Obtentor do bem, no tema do complô contra o ausente, pode-se entrar no drama do ponto de vista dessa força: a supressão provisória ou inicial do Obtentor do bem "é sobretudo dramática se a contextura do drama exige posteriormente a predominância do ponto de vista" dessa função. ${ }^{69}$ Recomenda ainda Souriau, na criação da cena, que se pergunte: "de que ponto de vista ela é a mais forte, a mais patética, a mais intensa... para mostrar? (...) o grande pressuposto artístico é, então, e antes de tudo a escolha da melhor perspectiva dramática". ${ }^{70}$

A questão do ponto de vista toca a questão da simpatia pelo personagem que o assume. Souriau preocupa-se em eliminar qualquer conotação afetiva ${ }^{71}$ da questão e esclarece:

Ele é simpático, nāo necessariamente no sentido de que nós (nós espectador ou nós autor) nos tomamos de simpatia por ele, de afeição, de preferência, mas no sentido de que, queiramos ou não, é através dos seus olhos - em simpatia, isto é, em correspondência privilegiada com ele - que vemos o universo cênico, é em relação a ele que

\footnotetext{
${ }^{63}$ Entre parênteses encontra-se a força não duplicada, isto é, que não conta com Adjuvante.

${ }^{54}$ SOURIAU. As duzentas mil situações dramáticas, p.53.

${ }^{65}$ IBIDEM. p.84-85.

${ }^{66}$ IBIDEM. p.85.

${ }^{67}$ IBIDEM. p.86.

${ }^{68}$ IBIDEM. p.68.

${ }^{69}$ IBIDEM. p. 142

${ }^{70}$ IBIDEM. p. 136.

${ }^{11}$ Na supressão do Obtentor do bem, Souriau dá um exemplo de herói, protagonista do ponto de vista, não

"simpático", no sentido vulgar do termo (p. 143).
} 
somos impressionados pela situação; é nele que — mesmo com horror - colocamos o centro perceptivo e apreciativo. Existe, se quisermos, simpatia, mas no sentido de uma correspondência privilegiada, de uma participação por assimilação. ${ }^{72}$

Para determinar o ponto de vista, Souriau chama a atenção para as indicações cênicas. A encenação, segundo suas palavras, é capaz de reforçar, precisar o que o texto implica. Acrescenta:

Ao inventarem, ao pensarem geralmente suas obras junto com a encenação, eles tomam partido franco e forte a este respeito, e prevêem os recursos técnicos, como homens que conhecem seu ofício ou que o sentem intensamente. ${ }^{73}$

E para confirmar o valor estético do ponto de vista conclui:

Nisto consiste toda a arte teatral (e, sob esse aspecto, até mesmo a arte literária em geral): descobrir sob que ângulo de visão o mundo a ser apresentado é o mais interessante, o mais pitoresco, o mais estranho, o mais vibrante, ou o mais significativo. É exatamente - a analogia é esclarecedora - fazer no moral o que o cineasta faz no físico com sua câmara, procurando o melhor ângulo de tomada. ${ }^{74}$

Da síntese ${ }^{75}$ acima, destacando as expressões que denotam apreciação, percebe-se o fio condutor das propriedades estéticas na elaboração da teoria das situações dramáticas. Não se trata de uma abordagem para tão somente determinar ou descobrir as funções que se encarnam nos personagens e para se chegar a um esquema actancial das cenas ou da peça na íntegra. Constitui-se numa teoria que ilumina, segundo pressupostos estéticos, os caminhos da invenção dramática, da encenação, da crítica teatral.

\section{ALGUNS COMENTÁRIOS}

Como experiência de forças geradoras de situaçōes, Souriau exemplifica com a seguinte combinação:

- um personagem, protagonista do ponto de vista, encarna as funçōes de Obtentor do bem, de Árbitro e de Oponente;

- um segundo personagem encarna a Força temática orientada e o Representante de bem desejado;

- um terceiro personagem encarna o Adjuvante da Força temática orientada; que ele próprio explica:

o segundo personagem deseja para outro o bem que ele próprio representa; o protagonista do ponto de vista tem o poder de decidir, resiste, mas acaba aceitando o bem; o terceiro personagem auxilia o segundo;

e interpreta:

\footnotetext{
${ }^{72}$ SourIau. As duzentas mil situações dramáticas, p.86.

${ }^{73}$ Convém lembrar Aristóteles, na Poética: "É preciso compor os enredos... colocando-os o mais possível diante dos olhos" (55 a 22)

${ }^{74}$ SOURIAU. As duzentas mil situaçōes dramáticas, p.92.

${ }^{75}$ Trata-se de síntese apenas do núcleo de As duzentas mil situaçōes dramáticas: o estudo das situações.
} 
essa situação, cujo tema é a tentação, sintetiza o drama ocorrido no Éden: Eva, contando com a ajuda da serpente, quer dar-se a Adão, que, com o poder de decisão, de início resiste, mas depois aceita. ${ }^{76}$

Trata-se de uma possível leitura do "drama humano original (segundo a Escritura)", ${ }^{77}$ conforme as palavras do próprio Souriau. No entanto, essa leitura pressupõe uma ideologia, que inclui uma concepção da mulher como tentadora, capaz de seduzir o homem e de fazê-lo desejar o que ela deseja, apesar de ele ter o poder decisório.

Suponhamos uma leitura desse drama, que atribua à serpente a função de Força temática orientada, e que:

Representante do bem desejado seja o fruto da ciência do bem e do mal,

Obtentor do bem e Árbitro, Adão,

Oponente, Deus,

Adjuvante, Eva,

continua havendo a tentação, mas subordinada ao tema da rivalidade, no caso, entre entidades transcendentes. Temos, então, uma leitura orientada pela ideologia judaico-cristã.

A criação de um drama, portanto, depende de uma concatenação de situaçōes geradas por combinações de funções, mas com uma indispensável orientação ideológica, que não pode ser esquecida nem pela encenação, nem pela crítica.

Souriau considera a forma narrativa para conduzir à cena os acontecimentos que se passam fora dela imperfeição grave do sistema. ${ }^{78} \mathrm{Cita}$, como exemplo, Terâmenes, no final da Fedra de Racine, narrando a Teseu a morte de Hipólito. Trata-se de uma avaliação que não leva em conta a especificidade de certas composições dramáticas, nem a ausência ou a precariedade de recursos cênicos em certas épocas. Num teatro, como o da tragédia grega, por exemplo, em que prevalece a unidade de lugar, a ação costuma depender muito do que se passa ou se passou fora do espaço da cena. Tornase imprescindível a articulação entre espaço mimético e espaço diegético. ${ }^{79}$ Qualquer tragédia grega interessa para mostrar essa articulação e algumas até para criticar empregos abusivos do recurso narrativo.

Vamos exemplificar com Édipo rei, por ser a tragédia mais presente nos espíritos, e para nos ater aqui a um emprego de narrativas bem articuladas com a ação. No espaço social de Édipo rei - que será sempre o mesmo: junto aos altares, diante do palácio - a primeira narrativa possibilita que se determine o bem desejado e quem o deseja: Édipo e o sacerdote com todo o povo desejam salvar a cidade da peste. Essa primeira situação dramática compōe-se em cena com a narrativa da peste. $\mathrm{O}$ diálogo que se segue mostra um Édipo que encarna a força que se orienta para um bem desejado, explicitando nessa orientação um tema: a salvação. $O$ que se vê no prólogo, portanto, é desencadeado pela narrativa, complementado por um diálogo que, de

\footnotetext{
${ }^{76}$ Souruau. As duzentas mil situaçōes dramáticas, p.107.

${ }^{77}$ IBIDEM. p. 108.

${ }^{78}$ IBIDEM. p. 18.

${ }^{79} \mathrm{Cf}$. IsSACHAROFF. Le spectacle du discours.
} 
certo modo, também narra, tornando conhecida a mensagem de Apolo, lembrando o assassínio de Laio, que não foi investigado porque as exigências da Esfinge absorveram as atençōes. Em suma, que é preciso, agora, para salvar a cidade, buscar o assassino de Laio.

No segundo episódio, há uma pequena narrativa de grande significado para a ação. Jocasta conta como salteadores teriam, numa bifurcação, assassinado Laio que, na previsão do oráculo, deveria morrer pelas mãos do filho; este, por causa dessa mensagem, fora exposto ainda recém-nascido, na montanha. O que se passa a ver em cena é um Édipo perturbado com uma preocupação provocada pela narrativa da morte de Laio. A bifurcação na estrada e as características de Laio levam Édipo a suspeitar de ser o assassino e, conseqüentemente, o culpado da peste. É o que explica a Jocasta também com uma narrativa na qual expõe o motivo que o fez deixar Corinto e como, em sua fuga, numa bifurcação da estrada, matou um velho, como o descrito pela rainha. Essas coincidências fazem-no exigir a presença do pastor que testemunhara o assassínio. Quando o pastor entra em cena, no entanto, vai prevalecer uma outra razão. A ação se bifurcou em duas buscas e a segunda superou a primeira. $O$ pastor vindo de Corinto com a mensagem da morte de Pólibo narra - - podemos dizer que narra, mesmo que seja em diálogo - que recebera Édipo recém-nascido de um pastor da casa de Laio e o levara a Mérope e Pólibo. Édipo volta, então, a sua primeira busca: a de sua identidade. Nessa mesma cena, por força do que o pastor de Laio narra - também em diálogo, porque, resistindo em revelar o que sabe, é instado a falar por perguntas e admoestações — os caminhos voltam a se encontrar. Assim como é a mesma pessoa o pastor que recebeu de Laio o menino para expô-lo e aquele que assistiu ao assassínio, assim também convergem as buscas para uma mesma pessoa: Édipo descobre sua identidade e descobre-se o assassino de Laio, e portanto, o culpado da peste. Vemos que as situaçōes dramáticas de cada episódio foram se encadeando com a interação do macrocosmo e do microcosmo, graças a narrativas que impunham modificações em cena e faziam a ação caminhar.

Parece-nos que as narrativas, quando propiciam essa interação e concatenação das situaçōes geradoras de ação, não se constituem, en absoluto, em recursos teatrais imperfeitos.

Quando Souriau reflete sobre o ponto de vista, chama a atenção para a importância que o dramaturgo deve dar à encenação, no momento da invençāo. ${ }^{80}$ Aristóteles coloca a criação teatral como um todo, sujeita à encenação, quando afirma que "é preciso compor os enredos... colocando-os o mais possível diante dos olhos". 81

O que está em cena não é importante apenas para o ponto de vista. Cada uma das funções dramatúrgicas pode ser esclarecida e mesmo determinada pela cena. Por exemplo, o bem desejado, em Coéforas, de Esquilo e nas Electra de Eurípides e Sófocles, aparece expressa em cena por signos visuais. Em Coéforas, o túmulo de Agamenão mostra a importância da memória do morto, em cuja reparação se empenha o herói;

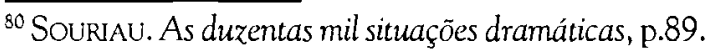

${ }^{81}$ Poética, 55 a 22.
} 
em Electra de Sófocles, há o palácio em cena e a heroína se empenha na recuperação do trono de Agamenão, embora não se esqueça da homenagem ao morto; em Electra de Eurípides, a cabana e a heroína andrajosa em cena reclamam a reparação da vida humilhante a que foi condenada a filha do rei.

Cada função dramatúrgica, portanto, requer uma elaboração em conjunto com os signos da cena.

\section{A}

RÉ SUMÉ

Cet article a pour but de montrer l'intérêt d'étudier Les deux cent mille situations dramatiques d'Etienne Souriau. D'abord, parce que cet ouvrage ne propose pas qu'un modèle actantiel formel de situations dramatiques, mais en examine les fonctions dramaturgiques selon des critères esthétiques. Il s'agit, en outre, d'une théorie utile à l'exercice dramaturgique, aussi bien qu'à l'évaluation critique et à la mise en scène de pièces.

\section{MOTS - CLÉ}

Souriau, situations dramatiques, modèle actantiel

\section{REFERÊNCIAS BIBLIOGRÁFICAS}

Fachin, Lídia. Théâtre et éducation chez George Sand. São Paulo: Faculdade de Filosofia, Letras e Ciências Humanas - Universidade de Sāo Paulo, 1984. (Tese de Doutorado)

Greimas, Algirdas-Julien. Semântica Estrutural, Pesquisa de método. Trad. Haquira Osakabe e Izidoro Blikstein. São Paulo: Cultrix/EDUSP, 1976.

Issacharoff, Michael. Le spectacle du discours. Paris: Librairie José Corti, 1985.

MONOD, Richard. Les textes de théâtre. Paris: CEDIC, 1977.

Pallottini, Renata. Dramaturgia. Construção do personagem. São Paulo: Ática, 1989.

PAvis, Patrice. Problèmes de sémiologie théâtrale. Québec: Les Presses de l'Université du Québec, 1976.

Ryngaert, Jean-Pierre. Introduçāo à análise do teatro. Trad. Paulo Neves. São Paulo: Martins Fontes, 1996.

Souriau, Etienne. As duzentas mil situações dramáticas. Trad. Maria Lúcia Pereira. São Paulo: Ática, 1993.

Ubersfeld, Anne. Le Roi et le Bouffon, Étude sur le théâtre de Hugo de 1830 a 1839. Paris: Librairie José Corti, 1974.

Ubersfeld, Anne. Lire le théâtre. Paris: Éditions Sociales, 1978. 